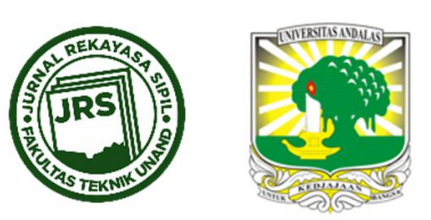

\title{
PREDIKSI LAJU SEDIMENTASI PADA SUNGAI JATIROTO
}

\author{
HAJAR C. CAHYANI ${ }^{1}$, ENTIN HIDAYAH ${ }^{1}$, RETNO U. A. WIYONO ${ }^{1}$, GUSFAN \\ HALIK $^{1}$, WIWIK Y. WIDIARTI ${ }^{1}$
}

${ }^{1}$ Jurusan Teknik Sipil, Fakultas Teknik, Universitas Jember. Jember, Jawa Timur, Indonesia *Corresponding author: $ه$ hajarcahyani27@gmail.com

Naskah diterima : 4 Februari 2020. Disetujui: 10 Februari 2021

\begin{abstract}
ABSTRAK
Erosi dapat menyebabkan terjadinya sedimentasi di sungai. Sedimentasi yang terjadi secara terusmenerus dapat mengakibatkan sungai menjadi dangkal dan mengurangi kapasitas sungai. Sedimen akan mengendap pada bagian tertentu di sepanjang aliran sungai yang tidak mampu terangkut bersama dengan aliran sungai. Sungai Jatiroto merupakan sungai yang membatasi Kabupaten Lumajang dan Kabupaten Jember. Sungai Jatiroto dimanfaatkan untuk keperluan irigasi pada kecamatan Jatiroto dan Kecamatan Rowokangkung. Penyebab dari sedimentasi adalah perubahan tata guna lahan ataupun erosi yang dilakukan oleh sungai itu sendiri. Pemodelan transpor sedimen oleh HEC-RAS bertujuan untuk mengetahui laju sedimen yang terbawa oleh sungai. Pada pemodelan ini dilakukan dua analisis, yaitu analisis hidrolika dan analisis transpor sedimen. Tahap pertama, analisis hidrolika menggunakan debit unsteady, parameter Manning (n) dan koefisien ekspansi dan kontraksi. Kalibrasi model dilakukan dengan cara perbandingan tinggi muka air yang menghasilkan nilai determinasi R2 sebesar 0,9586, nilai RMSE sebesar 0,39 dan masuk dalam kategori baik. Tahap kedua, analisis sedimentasi menggunakan debit quasi-unsteady dan diameter butiran. Fungsi pengangukatan sedimen yang cocok pada pemodelan ini adalah Laursen (Field) dengan laju sedimen sebesar 256,341 $\mathrm{m}^{3} /$ tahun. Adapun laju sedimentasi di lapangan dilakukan dengan membandingkan cross section lama dengan yang baru yaitu $289,24 \mathrm{~m}^{3} /$ tahun. Uji keandalan (validasi) model dilakukan dengan membandingkan hasil pemodelan dengan data observasi yang didapatkan dari hasil perhitungan volume pengendapan pada cross section. Didapatkan hasil uji keandalan sebesar $88 \%$.
\end{abstract}

Kata kunci : Sedimentasi; HEC-RAS; Sungai Jatiroto

\section{PENDAHULUAN}

Sungai Jatiroto merupakan sungai yang membatasi Kabupaten Lumajang dan Kabupaten Jember. Sungai Jatiroto dimanfaatkan untuk keperluan irigasi pada kecamatan Jatiroto dan Kecamatan Rowokangkung. Sedimentasi merupakan masalah yang sering terjadi pada sungai, penyebab dari sedimentasi adalah perubahan tata guna lahan. Ketika aliran tidak bisa mengangkut sedimen, maka sedimen tersebut akan diendapkan pada tempat tempat tertentu. Pengendapan sedimen dapat juga menyebabkan tingginya potensi banjir.

DOI : https://doi.org/10.25077/jrs.17.1.64-71.2021

Attribution-NonCommercial 4.0 International. Some rights reserved 
Penelitian mengenai sedimen telah dilakukan oleh banyak peneliti yang lain. Soesanto dan Susanti (2006) melakukan perhitungan volume sedimen menggunakan perbandingan volume sedimen pada tahun 1970-1977,1977-1982,1982-1988 dan 1988-1993 dengan mengambil volume terbesar yaitu pada tahun 1988-1993. Rosida dkk (2013) juga melakukan penelitian dalam perhitungan volume sedimen dengan metode cross section dan aplikasi lain. Perhitungan volume dengan menggunakan metode cross section dengan metode koordinat dan prismoida pada VBA yang terdapat dalam Ms.Excel memiliki ketelitian 101,597\% dibandingkan dengan $\mathrm{MC100} \%$ Perhitungan volume dengan menggunakan software Surfer 8 paling teliti adalah menggunakan metode gridding natural neighbour dengan ketelitian 99,794\%. Adapun Lestari (2018) melakukan penelitian sedimentasi menggunakan HECRAS dengan membandingkan cross section tahun 2001 dengan tahun 2018.

HEC-RAS adalah sistem software yang terintegrasi dan didesain untuk digunakan secara interaktif dalam kondisi tugas yang banyak macamnya. Sistem ini tersusun dari interface grafik pengguna, komponen analisa hidrolika terpisah, kemampuan manajemen dan tampungan data, fasilitas pelaporan dan grafik (Irawan, 2014). Analisis hidrolika aliran pada aplikasi HEC-RAS dibagi menjadi beberapa kategori, yaitu aliran permanen dan tidak permanen. Aplikasi HEC-RAS menggunakan persamaan yang berbeda untuk dua jenis aliran tersebut. Hasil simulasi transpor sedimen dari program HEC-RAS dapat digunakan dalam mengetahui bagian sungai yang mengalami kecenderungan terjadinya erosi.

HEC-RAS digunakan dalam melakukan pemodelan karena telah banyak dimanfaatkan dalam pemodelan aliran sungai dan sedimentasi. Haghiabi dan Zaredehdasht (2012) melakukan simulasi sedimen menggunakan HEC-RAS Sungai Karun di Iran, sedangkan Abdella dan Mekuanent (2021) melakukan membuat desain untuk mitigasi banjir di Sungai Kulfo, Ethiopia Selatan. Adapun Psomiadis et al. (2021) melakukan analisis kerusakan bendung dan asesmen risiko banjir menggunakan HEC-RAS, sedangkan Sennaoui et al. (2019) menggunakan HEC-RAS untuk melakukan renovasi saluran drainase.

Sungai Jatiroto memiliki kekhasan sendiri, yaitu pada suatu titik mengalami sedimentasi yang cukup besar daripada titik lainnya sehingga oleh masyarakat setempat dimanfaatkan untuk mengeruk pasir secara rutin. Berdasarkan latar belakang di atas, diperlukan penelitian untuk permasalahan-permasalahan tersebut tentang prediksi laju sedimentasi pada Sungai Jatiroto menggunakan program HEC-RAS5.0.7.

Keunggulan pada penelitian ini yaitu pada perhitungan volume pengendapan sedimen dengan perbandingan cross section tahun 2004 dan 2019 pada penampang yang mengalami agradasi degradasi. Selain itu titik yang ditinjau adalah titik yang mempunyai ciri khas sendiri pada Sungai Jatiroto karena pada titik tersebut sering dijadikan tempat penambangan pasir oleh masyarakat sekitar sehingga seiring berjalannya waktu, pada titik tersebut dapat mengalami agradasi dan degradasi. Penelitian ini akan bermanfaat untuk Balai DAS Bondoyudo dalam Menyusun panduan operasional Sungai Jatiroto.

\section{METODOLOGI PENELITIAN}

Penelitian ini dilakukan pada Sungai Jatiroto yang terletak di Kabupaten Lumajang, Provinsi Jawa Timur Gambar 1. Jatiroto merupakan kecamatan di Kabupaten Lumajang yang berbatasan langsung dengan Kabupaten Jember. Aliran sungai yang dimodelkan sepanjang $21 \mathrm{~km}$.

Penelitian ini menggunakan data primer dan data sekunder. Dilakukan analisis saringan pada data primer berupa sampel sedimen di Laboratorium Mekanika Tanah dan dilakukan 
pemetaan pada tiik cross section untuk mendapatkan data pengerukan yang nantinya digunakan untuk validasi data. Adapun data sekunder yang digunakan berupa data debit pada tahun 2018, data penampang memanjang dan penampang melintang Sungai Jatiroto setiap $100 \mathrm{~m}$ dari panjang sungai.

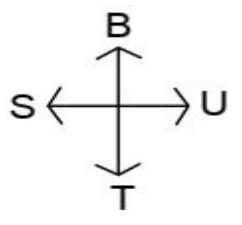

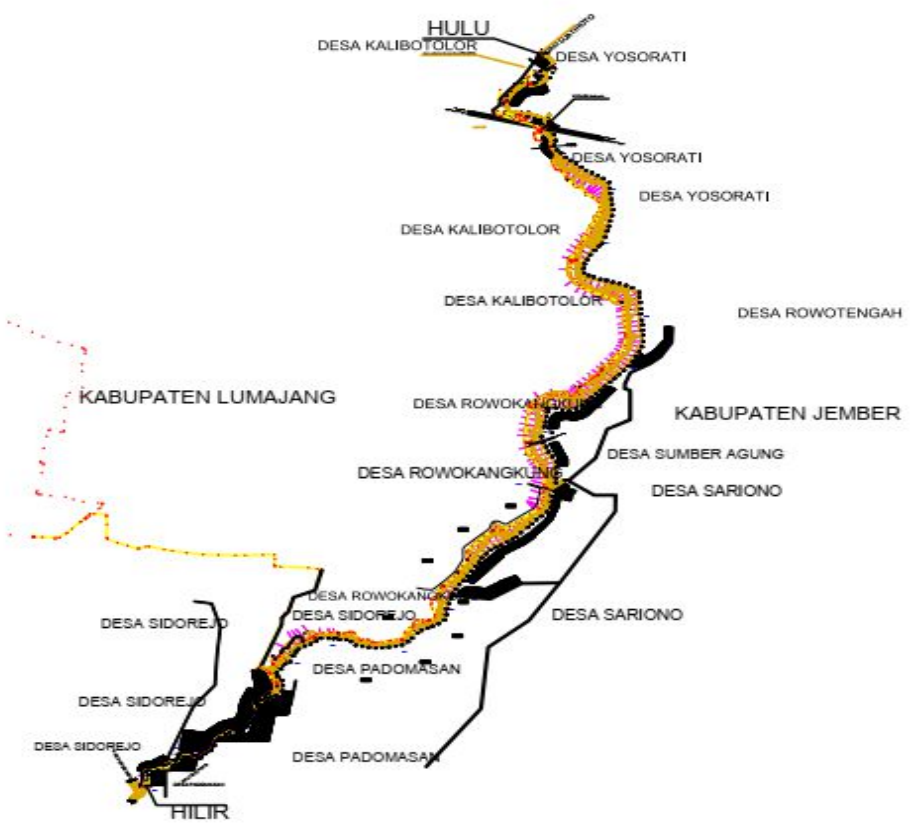

Gambar 1. Lokasi Penelitian di Kabupaten Lumajang (Dinas PU Lumajang, 2019)

Data diolah dengan program HEC-RAS menggunakan variabel-variabel dan parameter yang sudah didapatkan dari data primer dan data sekunder. Data tersebut akan digunakan untuk variabel data yang akan dimasukkan dalam program dan akan digunakan untuk simulasi pemodelan sedimentasi.. Data yang dimasukkan adalah data penampang, koefisien manning, koefisien ekspansi dan konstraksi, kemiringan dasar sungai, dan data debit aliran. Hasil dari analisis hidrolika adalah hasil tinggi muka air dan debit. Akan dilakukan kalibrasi tinggi muka air observasi (m) dengan data muka air pemodelan (m). Hasil simulasi akan di running kembali apabila hasil model tinggi muka air tidak sesuai dengan lapangan dengan cara mengubah beberapa parameter hidrolika seperti Koefisien Manning, Koefisien ekspansi dan konstraksi di HEC-RAS.

Setelah melakukan analisis hidrolika dan telah dilakukan kalibrasi hasilnya dengan hasil lapangan, maka dapat dilakukan input data untuk simulasi sediment transport. Untuk setting parameter model laju sedimen sesuai dengan: diameter butiran sedimen, kecepatan aliran, kedalaman Sungai. Pada penelitian ini menggunakan rumus pengangkutan Laursen (Field). Hasil yang diperoleh berupa besar laju sedimentasi yang terjadi. Lalu hasil simulasi akan di uji keandalan modelnya dengan data observasi lapangan dengan rumus presentase perbandingan hasil simulasi dan hasil observasi lapangan. 


\section{HASIL DAN PEMBAHASAN}

\subsection{Analisis Hidrolika}

Pemodelan menggunakan HEC-RAS untuk analisis hidrolika bertujuan untuk mengetahui kesesuaian geometri yang telah dimodelkan terhadap kondisi yang ada di lapangan. Analisis hidrolika ini menggunakan data debit pada kondisi unsteady flow dan data geometri sungai berupa penampang memanjang dan penampang melintang. Simulasi model pada analisis hidrolika menggunakan data debit sungai untuk batas hulu dan data krmiringan sungai pada hilir. Adapun parameter yang digunakan adalah koefisien Manning (n), koefisien ekspansi dan kontraksi. Nilai koefisien ekspansi dan kontraksi yang digunakan adalah 0,1 dan 0,3. Koefisien Manning ( $n$ )initial yang digunakan adalah 0,025 lalu Koefisien Manning ( $n$ )yang digunakan ialah 0,039. Didapatkan Tinggi muka air hasil pemodelan tersebut digunakan untuk kalibrasi model sebagai disajikan pada Tabel 1 dan Tabel 2 berikut.

Tabel 1. Koefisien Manning Saluran

\begin{tabular}{lc}
\hline Saluran Alam (Dataran Banjir) & $\mathbf{n}$ \\
\hline a. Padang Rumput Tanpa Belukar & \\
\hline Rumput pendek & $0,025-0,035$ \\
\hline Rumput tinggi & $0,03-0,05$ \\
\hline b. Daerah Pertanian & \\
\hline Tanpa tanaman & $0,02-0,04$ \\
\hline Tanaman dibariskan & $0,025-0,045$ \\
\hline Tanaman tidak dibariskan & $0,03-0,05$ \\
\hline
\end{tabular}

Tabel 2. Perbandingan Tinggi Muka Air Obsevasi dan Simulasi

\begin{tabular}{ccc}
\hline River Station(RS) & Observasi & Simulasi \\
\hline 20,2 & 1,81 & 1,57 \\
\hline 8 & 0,72 & 0,32 \\
\hline 1,5 & 1,48 & 1,44 \\
\hline Total & 4,01 & 3,33 \\
\hline
\end{tabular}

Nilai tinggi muka air observasi pada Tabel 1 didapatkan dari pengukuran secara langsung. Pengukuran diambil pada tanggal 23 September 2019 saat kondisi cuaca baik dan beberapa hari sebelum pengukuran tidak terjadi hujan (Gambar 2). Pengukuran dilakukan pada saat muka air sungai kering yang berarti tidak adanya pengaruh debit dari hulu. Titik ukur yang diambil adalah titik cross section pada bagian hulu, tengah, dan hilir.

Perbandingan tersebut memberikan nilai koefisien determinasi $\left(\mathrm{R}^{2}\right)$ sebesar 0,9586 (Gambar 3) yang tergolong sangat baik karena mendekati 1. Hasil dari perhitungan selanjutnya didapatkan nilai RMSE (Root Mean Square Errors) sebesar 0,39. Perhitungan standar error tersebut tergolong kecil karena masuk dalam kisaran 0,0-1,0. Semakin kecil nilai RMSE, maka semakin akurat pemodelan yang dilakukan. Oleh karena itu, dapat disimpulkan bahwa nilai koefisien Manningyang cocok pada kondisi tersebut adalah 0,039. Nilai koefisien tersebut bisa digunakan untuk simulasi selanjutnya. 


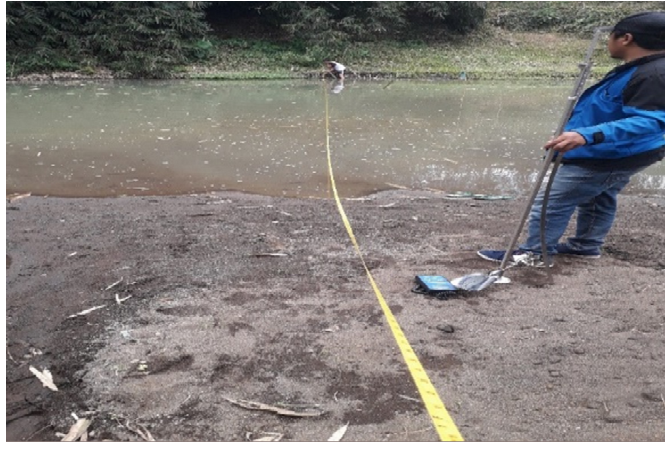

Gambar 2. Observasi Sungai

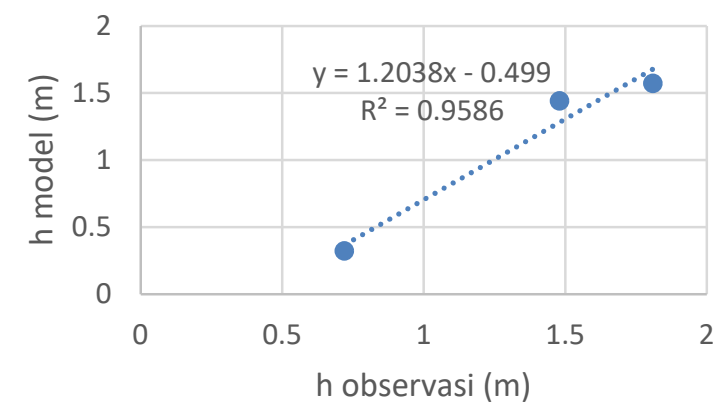

Gambar 3. Perbandingan Tinggi Muka Air Observasi dan Simulasi

\subsection{Analisis Sedimentasi}

Pemodelan transpor sedimen diawali dengan input data saringan butiran menggunakan saringan no. 4 hingga 200 didapatkan persentase butiran halus pada diameter 0,075 mm memiliki persentase lolos sebesar $0,14 \%$. Penyesuaian input gradasi sedimen adalah penyesuaian ukuran butiran sedimen pada keadaan sebenarnya (real condition) dengan ukuran butiran yang tersedia dalam program HEC-RAS. Butiran halus yang tertahan dengan persentase lolos hanya $0,14 \%$ pada diameter $0,075 \mathrm{~mm}$ menandakan bahwa butiran halus tersebut tergolong klasifikasi interval/range 0,125-0,0625 yaitu pasir sangat halus (Very Fine Sand) (Hydrologic Engineering Center, 2016). Klasifikasi butiran akan ditunjukkan pada Tabel 3.

Tabel 3. Penyesuaian Gradasi Sedimen Menurut American Geophysical Union

\begin{tabular}{lllll}
\hline & \multicolumn{2}{c}{ HEC-RAS } & \multicolumn{2}{l}{ Analisa Laboratorium } \\
\hline Material Sedimen & Rentang Ukuran & Nialai Tengah & Diameter \\
\hline Lumpur & Diameter (mm) & Diameter (mm) & Saringan (mm) & - \\
\hline Lanau sangat halus & $0,002-0,004$ & 0,003 & - & - \\
\hline Lanau halus & $0,008-0,008$ & 0,006 & - & - \\
\hline Lanau sedang & $0,016-0,032$ & 0,011 & - & - \\
\hline Lanau kasar & $0,032-0,0625$ & 0,023 & - & - \\
\hline Pasir sangat halus & $0,032-0,0625$ & 0,088 & - & 0,14 \\
\hline Pasir halus & $0,125-0,250$ & 0,177 & 0,075 & 0,3 \\
\hline Pasir kasar & $0,5-1,0$ & 0,707 & 0,6 & 31,38 \\
\hline Pasir sangat kasar & $1-2$ & 1,41 & 2 & 78,68 \\
\hline Kerikil sangat halus & $2-4$ & 2,83 & 2,36 & 91,56 \\
\hline Kerikil halus & $4-8$ & 5,66 & 4,75 & \\
\hline
\end{tabular}

Data debit yang digunakan dalam running model adalah data debit quasi-unsteady untuk waktu simulasi 1 tahun pada tahun 2018. HEC-RAS menyediakan 7 fungsi pengangkutan sedimen antara lain Ackers-White (Flume), England-Hansen (Flume), Laursen (Field), Laursen (Flume), Meyer-Peter-Muller (Flume), Tofaletti (Field), Tofaletti (Flume), Yang (Field-Sand), dan Yang (Field-gravel). Penentuan fungsi pengangkutan sedimen didapatkan dari data variabel yang disediakan oleh HEC-RAS kemudian dicocokkan dengan data observasi berupa diameter butiran (d, mm), kecepatan aliran $(\mathrm{V}, \mathrm{m} / \mathrm{s})$, dan lebar saluran (W, $\mathrm{m}$ ). Fungsi pengangkutan sedimen yang didapatkan dari kecocokan data adalah fungsi pengangkutan Laursen (field) yang dipilih sesuai kondisi sedimen sungai (kecepatan aliran dan diameter butiran). Dengan metode persamaan tersebut akan dikerahui kumulatif total sedimen yang masuk dalam satuan ton selama periode simulasi. Hasil simulasi pada HEC- 
RAS dapat diketahui pada RS 20,200 akhir simulasi mendapatkan nilai sebesar 358,878 ton/tahun. Apabila dikonversikan menghasilkan nilai sebesar 256,341 $\mathrm{m}^{3}$. Program HECRAS mempunyai fungsi yaitu untuk mengetahui kondisi yang akan terjadi setelah masa simulasi tersebut. Perubahan titik-titik pada tampang lintang yang tidak terlalu signifikan membuktikan bahwa selisih sedimen yang masuk pada tampang melintang (Cross Section) tidak terlalu mempengaruhi bentuk dari penampang melintang tersebut. Namun, seiring berjalannya waktu, sedimen akan terus menumpuk apabila tidak adanya pengendalian

\subsection{Uji Keandalan}

Simulasi yang dilakukan menghasilkan volume total sedimen yang berbeda disetiap tampang melintang. Untuk mendapatkan keandalan model, dapat dilakukan perbandingan data observasi dengan data hasil simulasi. Data observasi yang dibandingkan adalah data cross section pada STA 20,200 tahun 2004 dengan data cross section tahun 2019 yang dapat dilihat pada Gambar 4.

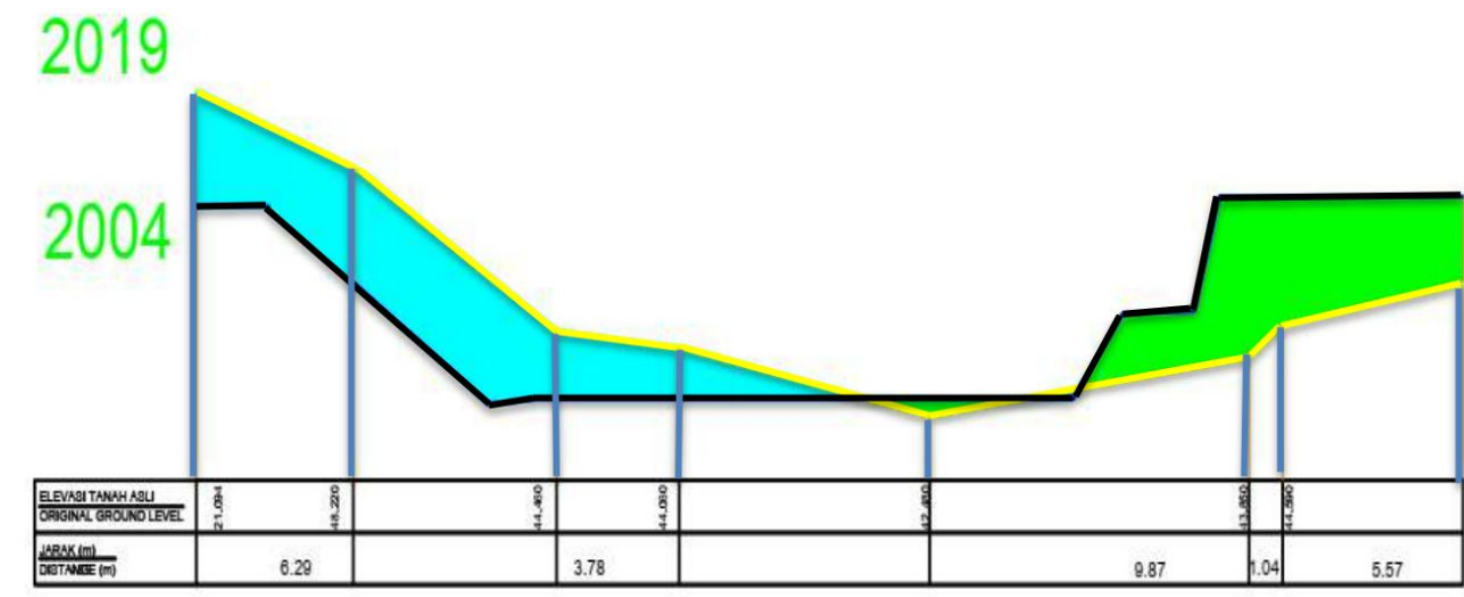

$\begin{array}{ll}\text { Keterangan : } & \\ \text { Biru } & =\text { Agradasi } \\ \text { Hijau } & =\text { Degradasi } \\ \text { Garis hitam } & =\text { Cross Section 2004 } \\ \text { Garis Kuning } & =\text { Cross Section 2019 }\end{array}$

Gambar 4. Perbandingan Penampang Sungai STA 20,200 pada 2004 dan 2019

Berdasarkan Gambar 4 dapat diketahui bahwa pada STA 20,200 terjadi agradasi dan degradasi. Didapatkan data volume yang mengendap (agradasi) dari perbandingan penampang melintang tahun 2004 dan penampang melintang tahun 2019 sebesar 289,24 $\mathrm{m}^{3}$. Berdasarkan hasil simulasi sedimen HEC- RAS pada STA 20,200 diperoleh laju sedimentasi $256,341 \mathrm{~m}^{3} /$ tahun, sehingga dapat diketahui presentase keandalan model menggunakan perbandingan data simulasi dengan data lapangan yaitu

Keandalan Model $=\frac{\text { Volume Simulasi }}{\text { Volume Observasi }} \times 100 \%=\frac{256,341}{289,24} \times 100 \%=88 \%$

Presentase keandalan model sebesar $88 \%$ masih mungkin ditingkatkan jika digunakan cross section yang lebih rapat. Terjadi agradasi dan degradasi di beberapa bagian sungai dan didapatkan volume pengerukan sebesar $1.022,843 \mathrm{~m}^{3}$. Pada penelitian ini, bagian cross section sungai di titik STA 20,200 juga mengalami agradasi dan degradasi, namun 
kekhususan yang terjadi dilokasi penelitian ini adalah hanya bagian kiri sungai yang mengalami degradasi, sedangkan untuk bagian kanan sungai mengalami agradasi.

Terjadinya degradasi pada bagian kiri disebabkan adanya scouring karena terdapat belokan pada bagian tersebut dan bagian kiri merupakan sisi luar dari belokan tersebut. Selain itu, pengambilan pasir biasa dilakukan pada bagian tengah dan sanping kiri sungai pada STA 20,200 tersebut. Pada bagian kanan sungai terjadi agradasi dikarenakan terjadinya sedimentasi pada sisi dalam belokan sungai.

\section{KESIMPULAN DAN SARAN}

Pada penelitian ini didapatkan prediksi laju sedimentasi pada Sungai Jatiroto dalam analisis hidrolika menghasilkan nilai determinasi $\left(\mathrm{R}^{2}\right)$ sebesar 0,9586 yang tergolong dalam kategori sangat baik karena nilai mendekati 1, dengan nilai RMSE sebesar 0,39 yang memiliki standar error kategori kecil karena masuk dalam kisaran 0,0-1,0. Sedangkan pada analisis sedimentasi, hasil simulasi HEC-RAS menggunakan fungsi pengangkutan Laursen (Field) menghasilkan laju sedimen sebesar $256,341 \mathrm{~m}^{3} /$ tahun dengan nilai keandalan model sebesar $88 \%$.

Prediksi laju sedimentasi menggunakan HEC-RAS 5.0.7 ini masih menggunakan pendekatan 1 dimensi sehingga masih memiliki keterbatasan. Untuk mendapatkan hasil yang lebih baik dapat dilakukan pemodelan menggunakan software Surface Water Modelling Sysem (SMS), software SWAT (Soil and Water Assesment Tool) dan software lainnya. Selain itu, penelitian selanjutnya dapat juga menganalisa penanganan yang tepat untuk masalah sedimentasi yang terjadi pada Sungai Jatiroto.

\section{UCAPAN TERIMAKASIH}

Penelitian ini dapat terlaksana atas hibah Kelompok Riset Hidroteknik tahun 2019 dari Lembaga Penelitian dan Pengabdian kepada Masyarakat (LP2M) Universitas Jember. Ucapan terima kasih disampaikan kepada UPT PSDA WS Bondoyudo Baru dan UPT Jatiroto dan pihak- pihak yang telah membantu dalam survei lapangan dan pemetaan cross section Sungai Jatiroto.

\section{DAFTAR PUSTAKA}

Abdella, K., \& Mekuanent, F. (2021). Application of hydrodynamic models for designing structural measures for river flood mitigation: the case of Kulfo River in southern Ethiopia. Modeling Earth Systems and Environment, 1-13.

Dinas PU Lumajang. (2019). Kontur Kali Jatiroto.

Haghiabi, A. H., \& Zaredehdasht, E. (2012). Evaluation of HEC-RAS ability in erosion and sediment transport forecasting. World Applied Sciences Journal, 1久(11), 1490-1497.

Hydrologic Engineering Center. (2016). HEC-RAS River Analysis System. Hydraulic Reference Manual. Version 5. February 2016. https://www.hec.usace.army.mil/software/hecras/documentation/HEC-RAS 5.0 Reference Manual.pdf

Irawan, E. S. (2014). Analisis Pemodelan Sedimentasi di Saluran Kencong Timur (BEDODO) Menggunakan Program HEC-RAS. Fakultas Teknik Jurusan Teknik Sipil Universitas Jember.

Lestari, P. W. (2018). Studi Laju Sedimentasi Pada Sungai Bedadung Menggunakan Program HecRas 5.O. 5. Fakultas Teknik Universitas Jember.

Psomiadis, E., Tomanis, L., Kavvadias, A., Soulis, K. X., Charizopoulos, N., \& Michas, S. (2021). Potential dam breach analysis and flood wave risk assessment using HEC-RAS and remote sensing data: A multicriteria approach. Water, 13(3), 364.

Rosida, A., Kahar, S., \& Awaluddin, M. (2013). Perbandingan Ketelitian Perhitungan Volume Galian Menggunakan Metode Cross Section Dan Aplikasi Lain (Studi Kasus: Bendungan Pandanduri 
Hajar C. Cahyani, Entin Hidayah, Retno U. A. Wiyono, Gusfan Halik, Wiwik Y. Widiarti

Lotim). Jurnal Geodesi Undip, 2(3).

Sennaoui, F., Benabdesselam, T., \& Saihia, A. (2019). Use of modelling for the renovation of drainage channels-The case of the Bouteldja plain in northeastern Algeria. Journal of Water and Land Development, 43(1), 1-8.

Soesanto, M. H., \& Susanti, T. (2006). Evaluasi Sedimen di Waduk Selorejo dan Alternatif Penanganannya. Fakultas Teknik, Universitas Diponegoro. 